Nurul Hafizah ${ }^{\text {I) , Maya Ariyanti }}{ }^{2)}$ /JMM Online Vol. 3 No. 1 Januari (2019) 16-28

\begin{tabular}{cr} 
Jurnal Mitra Manajemen (JMM Online) & $\begin{array}{c}\text { JMM Online } \\
\text { URL:http://e-jurnalmitramanajemen.com }\end{array}$ \\
Vol. 3, No. 1, 16-28. \\
O 2019 Kresna BIP. \\
ISSN 2614-0365 \\
e-ISSN 2599-087X \\
\hline
\end{tabular}

\title{
PENGARUH THE PUBLIC GOOD DAN KNOWLEDGE SELF-EFFICACY TERHADAP NIAT KONSUMEN MELAKUKAN ELECTRONIC WORD OF MOUTH (E-WOM)
}

(Studi pada Pengguna Kaskus di Indonesia)

\author{
Nurul Hafizah ${ }^{1)}$, Maya Ariyanti ${ }^{2)}$ \\ Universitas Telkom
}

INFORMASI ARTIKEL

Dikirim : 07 Desember 2018

Revisi pertama : 10 Januari 2019

Diterima : 12 Januari 2019

Tersedia online : 31 Januari 2019

Kata Kunci : Niat melakukan e-WOM, Kenikmatan Membantu, Rasa Memiliki, Reputasi

Email:nurulhfizah@yahoo.com ${ }^{1)}$, letterbox.maya@gmail.com ${ }^{2)}$

\section{ABSTRAK}

Kemajuan jaringan internet WWW mampu memberikan pilihan informasi mengenai suatu produk, memungkinkan adanya sebuah komunikasi word-of-mouth yang tidak hanya menjadi sebuah bentuk komunikasi person-to-person namun juga memberikan kesempatan untuk merambat secara mendunia melalui media online yang biasa dikenal dengan Electronic Word of Mouth ( $e$ WOM). Komunikasi e-WOM dapat dilakukan melalui online opinion platforms atau discussion forums, salah satunya adalah Kaskus.

Dalam tulisan ini, penulis fokus pada faktor-faktor yang mempengaruhi niat konsumen melakukan e-WOM di Kaskus. Penulis mengidentifikasi motif utama dari niat eWOM konsumen yaitu Egoisme (reputasi dan timbal balik), Collectivism (rasa memiliki), Altruism (kenikmatan membantu), Prinsiplism (prinsip moral) dan Knowledge Self-Efficacy.

Penulis menguji model penelitian dengan sampel 100 pengguna/member Kaskus di Indonesia. Dalam penelitian ini analisis data menggunakan pendekatan Partial Least Square (PLS) dengan menggunakan software Smart PLS 3 for windows. Hasil dari penelitian ini menunjukkan $27.9 \%$ varians dengan kenikmatan membantu, rasa memiliki dan reputasi berhubungan positif dengan niat konsumen melakukan e-WOM. 


\section{PENDAHULUAN \\ Latar Belakang}

Dengan kemajuan teknologi yang pesat khususnya jaringan internet WWW (World Wide Web) yang mampu memberikan pilihan-pilihan informasi mengenai suatu produk memungkinkan adanya sebuah komunikasi word-of-mouth yang tidak hanya menjadi sebuah bentuk komunikasi person-to-person namun juga memberikan kesempatan untuk merambat secara mendunia melalui media online yang biasa dikenal dengan Electronic Word of Mouth (e-WOM) (Jalilvand dan Samiei, 2012). Komunikasi e-WOM mampu membuat konsumen tidak hanya mendapatkan informasi mengenai produk dan jasa terkait dari orang-orang yang mereka kenal, namun juga dari sekelompok orang yang berbeda area geografisnya yang memiliki pengalaman terhadap produk atau jasa yang dimaksud (Cheung dan Lee, 2012). Komunikasi e-WOM dapat dilakukan melalui online customer-opinion platform. Salah satu online opinion platforms atau discussion forums yang dapat digunakan untuk melakukan komunikasi e-WOM adalah Kaskus. Kaskus merupakan forum diskusi \& jual beli terbesar di Indonesia dan menjadi rumah bagi siapa saja untuk menemukan segala hal yang mereka butuhkan. Jutaan orang menggunakan Kaskus untuk mencari informasi, pengetahuan, bergabung dengan komunitas baru, hingga jual beli segala jenis barang dan jasa dengan harga terbaik. Kemitraan Kaskus dengan Global Digital Prima mendorong pertumbuhan Kaskus yang lebih besar, baik dari sisi infrastuktur, tenaga profesional \& jaringan bisnisnya dalam usaha menjadi situs lokal nomor satu di Indonesia serta pemain global on line di dunia. (https://bantuan.kaskus.co.id).

Mannase (2018) Kaskus memiliki kategori forum diskusi yang paling beragam, antara lain the lounge, games, movie, technologi, bisnis dan lain sebagainya. Kemudian posisi kedua ditempati oleh Kompasiana yaitu salah satu forum internet tempat orangorang melakukan diskusi seputar hal mengenai politik atau pendidikan. Melalui Kaskus semua orang dapat menikmati salah satu fasillitas utama yang ditawarkan oleh Kaskus, yaitu forum diskusi. Melalui forum diskusi tersebut nantinya setiap orang akan dapat memberikan maupun menerima informasi mengenai hal apapun, serta dapat sekaligus mencari barang yang ingin mereka beli. Melalui forum diskusi ini setiap orang dapat membagikan pengalaman mereka mengenai semua hal seperti fasilitas-fasilitas umum seperti taman yang pernah mereka gunakan maupun barang-barang pribadi seperti makanan, pakaian dan lain-lain yang termasuk kedalam public good. e-WOM/Review yang dilakukan seseorang biasanya terjadi tanpa permintaan dari orang lain atau instansi yang bersangkutan.

Untuk menguatkan bahwa pengguna/member Kaskus menggunakan Kaskus untuk berbagi pengalaman mengenai suatu produk/jasa yang sudah pernah mereka gunakan melalui forum diskusi Kaskus maka penulis melakukan pra-penelitian kepada 44 responden yang merupakan pengguna/member Kaskus dan sudah pernah melakukan interaksi dengan pengguna/member lain di Kaskus. Dari 44 responden, terdapat 37 responden yang merupakan pengguna/member Kaskus, namun hanya terdapat 30 responden yang pernah melakukan interaksi dengan pengguna/member lain di Kaskus. Artinya ada sebagian member Kaskus yang mendaftarkan akun mereka untuk kepentingan lain, misalnya hanya untuk mencari informasi saja tanpa melakukan interaksi dengan member lain. 
Disamping itu, hasil pra-penelitian menunjukkan bahwa 25 responden melakukan interaksi di Kaskus untuk membagikan pengalaman mereka mengenai suatu produk/jasa yang pernah mereka gunakan dan 5 responden lain melakukan interaksi untuk proses jual/beli di Kaskus. Artinya sebagian besar member Kaskus benar melakukan interaksi di Kaskus untuk membagikan pengalaman mereka mengenai suatu produk/jasa yang pernah mereka gunakan. Dari 25 responden yang melakukan interaksi di Kaskus untuk membagikan pengalaman mereka mengenai suatu produk/jasa yang pernah mereka gunakan, mereka cenderung membagikan pengalaman mengenai barang publik dan barang pribadi seperti, fasilitas umum, makanan, minuman, tempat tinggal, pakaian dan lain-lain.

Kemudian responden yang melakukan interaksi di Kaskus untuk membagikan pengalaman mereka mengenai suatu produk/jasa yang pernah mereka gunakan, cenderung merasa bahwa mereka mempunyai pengetahuan yang tinggi mengenai produk/jasa yang akan mereka bagikan tersebut. Selain membagikan pengalaman, para responden juga cenderung mencari informasi mengenai suatu produk/jasa tertentu dari pengguna/member lain di Kaskus.

Dari hasil pra-penelitian tersebut, dapat dilihat bahwa pengguna/member Kaskus cenderung membagikan pengalaman mengenai barang publik dan barang pribadi seperti, fasilitas umum, makanan, minuman, tempat tinggal, pakaian dan lain-lain. Hal ini sejalan dengan definisi bahwa public good tidak hanya mencakup barang yang disediakan oleh pemerintah maupun swasta yang dapat digunakan oleh lebih dari satu orang (fasilitas umum, taman, informasi, air dan lain-lain), melainkan juga barang pribadi yang hanya digunakan oleh satu orang (makanan, pakaian, tempat tinggal dan lain- lain) (Baston, 1994; dalam Cheung dan Lee 2012).

Dalam penyediaan public good sendiri, terdapat masalah yang muncul dan menjadi masalah sosial yang cukup besar. Salah satu masalahnya, yaitu mereka yang ikut menikmati public good tanpa mengeluarkan kontribusi tertentu, sementara sebenarnya ada pihak lain yang berkontribusi untuk mengadakan public good tersebut. Orang-orang yang mau melakukan kontribusi biasanya adalah mereka yang mempunyai pengetahuan yang tinggi atas sesuatu hal yang berkaitan dan memiliki kepercayaan yang tinggi atas sesuatu hal yang akan mereka lakukan tersebut, hal ini disebut dengan knowledge self-efficacy (Cheung dan Lee, 2012).

Kontribusi yang dapat dilakukan oleh orang-orang/konsumen adalah dengan memberikan informasi mengenai barang publik seperti produk/jasa tertentu dengan memberikan ulasan yang diperuntukkan untuk orang lain atau bisa dikenal dengan Electronic Word of Mouth (e-WOM) (Cheung dan Lee, 2012). e-WOM menjadi sebuah "venue" atau sebuah tempat yang sangat penting untuk konsumen memberikan opininya dan dianggap lebih efektif dibandingkan WOM offline, karena tingkat aksesibilitas dan jangkauannya yang lebih luas (Jalilvand dan Samiei, 2012).

Sebenarnya dalam hal ini, tidak berkontribusi untuk publik memang benar menciptakan masalah besar bagi masyarakat, namun berkontrbusi untuk publik pun menciptakan masalah besar bagi para ilmuwan perilaku dan sosial. Masalahnya adalah mengapa orang-orang/konsumen melakukan suatu kontribusi (Baston, 1994; dalam Cheung dan Lee, 2012). Dalam penelitiannya, Cheung dan Lee (2012) mengemukakan orang-orang melakukan kontribusi untuk public good karena didasari oleh faktor 
Egoism (Reputasi dan Timbal Balik), Collectivism (Rasa Memiliki), Altruism (Kenik matan Membantu), Prisiplism (Kewajiban Moral) dan Knowledge Self-Efficacy.

Penelitian terdahulu yang dilakukan oleh Cheung dan Lee (2012) didapatkan hasil bahwa faktor pendorong konsumen melakukan e-WOM yaitu kenikmatan membantu, rasa memiliki dan reputasi. Dengan online customer-opinion platform (forum diskusi online) yang berbeda, maka penulis ingin melakukan penelitian untuk mengetahui niat konsumen melakukan e-WOM yang dipengaruhi oleh public good dan knowledge self-efficacy. Selain itu, penulis ingin mengetahui apakah dimensi-dimensi yang telah dikemukakan oleh Cheung dan Lee (2012) memiliki hubungan yang sama dengan objek penelitian penulis, yaitu Kaskus. Penelitian ini akan dilakukan dengan judul "Hubungan Antara The Public Good dan Knowledge Self-Efficacy Dengan Niat Konsumen Melakukan Electronic Word of Mouth (e-WOM) (Studi pada Pengguna Kaskus Di Indonesia)".

\section{Rumusan Masalah}

Berdasarkan penjelasan pendahuluan diatas maka rumusan masalah pada penelitian ini adalah sebagai berikut:

1. Apakah terdapat pengaruh positif antara persepsi reputasi, timbal balik, rasa memiliki, kenikmatan membantu, prinsip moral dan knowledge self efficacy terhadap niat konsumen untuk melakukan Electronic Word of Mouth (e-WOM) melalui Kaskus?

2. Seberapa besar reputasi, timbal balik, rasa memiliki, kenikmatan membantu orang lain, prinsip moral, dan knowledge self efficacy berpengaruh terhadap niat konsumen melakukan electronic word of mouth (e-WOM) melalui Kaskus?

\section{Tujuan Penelitian}

Penelitian ini dilakukan dengan tujuan sebagai berikut, yaitu :

1. Mengetahui pengaruh positif persepsi reputasi, timbal balik, rasa memiliki, kenikmatan membantu, prinsip moral dan knowledge self efficacy terhadap niat konsumen untuk melakukan Electronic Word of Mouth (e-WOM) melalui Kaskus;

2. Mengetahui besar pengaruh reputasi, timbal balik, rasa memiliki, kenikmatan membantu orang lain, prinsip moral, dan knowledge self efficacy terhadap niat konsumen melakukan electronic word of mouth (e-WOM) melalui Kaskus.

\section{KAJIAN PUSTAKA}

\section{Komunikasi Word of Mouth (e-WOM)}

Komunikasi word of mouth dapat mengarah ke ranah komunikasi pemasaran (Prisgunanto, 2014:115). Kotler dan Keller (2016a) menyatakan bahwa komunikasi word of mouth (WOM) adalah sebuah proses komunikasi untuk rekomendasi tertentu baik secara individu atau dalam kelompok pada sebuah produk atau jasa yang ditujukan untuk menyediakan informasi pribadi.

Sunyoto (2015:161) juga menjelaskan bahwa word of mouth merupakan informasi dari pelanggan lain atau masyarakat lainnya tentang pengalaman menggunakan produk yang dibelinya. Hasan (2013:28) juga menyatakan bahwa word of mouth adalah jenis komunikasi yang berpengaruh besar terhadap keputusan dan 
perubahan perilaku pelanggan. Dari keempat definisi mengenai WOM diatas dapat disimpulkan bahwa WOM merupakan kegiatan memberikan informasi kepada orang lain baik dalam bentuk rekomendasi dan berbagi pengalaman mengenai suatu produk atau jasa kepada orang lain.

\section{Komunikasi Electronic Word of Mouth (e-WOM)}

Kotler dan Keller (2016b:278) menyatakan bahwa viral marketing adalah bentuk online word of mouth, yang mendorong konsumen untuk menyampaikan pelangalaman mereka mengenai produk dan layanan yang dikembangkan perusahaan atau informasi audio, video, atau tertulis kepada orang lain secara online. Dengan situs konten yang dibuat pengguna seperti youtube, vimeo, dan video google, konsumen dan pengiklan dapat mengunggah iklan dan video untuk dibagikan kepada jutaan orang.

Henning-Thurau dkk. dalam Wijaya dan Paramitha (2014:14) menyatakan bahwa e-WOM merupakan pernyataan positif atau negatif yang dibuat oleh pelanggan potensial, pelanggan aktual dan mantan pelanggan tentang produk atau perusahaan melalui internet. Definisi lain dikemumukan oleh Cheung dan Lee (2012) bahwa komunikasi e-WOM merupakan pernyataan positif, netral, maupun negatif dari konsumen potensial, aktual, maupun mantan konsumen mengenai produk, jasa, merek, atau perusahaan yang tersedia untuk banyak orang dan lembaga melalui internet.

\section{Perbedaan WOM Dan e-WOM}

Electronic Word of Mouth (e-WOM) merupakan digitalisasi dari WOM tradisional. WOM disampaikan secara langsung dari satu pihak ke pihak lain, sedangkan penyampaian e-WOM membutuhkan media perantara yaitu melalui media elektronik. WOM pada dasarnya berisikan informasi yang akurat, emosional, lebih jujur dan hanya dapat diperoleh sekali saja karena prosesnya terjadi langsung dan berasal dari sumber yang dipercaya contohnya keluarga. Sedangkan e-WOM belum tentu berisi informasi yang akurat karena berasal dari sumber yang cenderung tidak dikenal (misalnya sesama pengguna internet dan media sosial tertentu) namun mempunyai kelebihan yaitu dapat disimpan sebagai arsip jika sewaktu-waktu dibutuhkan dan penyebarannya pun sangat cepat bahkan dapat meluas secara global (Humaira dan Wibowo, 2016).

\section{The Public Good}

Public good tidak hanya mencakup barang dari para ekonom, barang-barang yang dapat digunakan oleh lebih satu orang (jalan raya, taman, informasi, udara bersih dan lain-lain), tetapi juga barang-barang pribadi, barang-barang yang dapat digunakan hanya oleh satu orang (makanan, pakaian, tempat tinggal dan lain-lain) (Baston, 1994; dalam Cheung dan Lee, 2012).

Sebuah barang publik ditandai sebagai "Sumber daya bersama dimana setiap anggota kelompok dapat meraih keuntungan, terlepas dari apakah secara pribadi mereka berkontribusi atau tidak atas penyediaan, dan ketersediaan dalam penggunaannya (Cabrera, 2002; dalam Cheung dan Lee, 2012). 


\section{Knowledge Self Efficacy}

Individu cenderung memberikan saran yang berguna pada jaringan komputer jika mereka memiliki tingkat keahlian yang tinggi. Sebaliknya, ketika mereka kekurangan informasi atau pengetahuan yang berguna bagi orang lain, mereka cenderung kurang memberi kontribusi dalam berbagi pengetahuan karena, misalnya, mereka percaya bahwa mereka tidak dapat memberi dampak positif bagi organisasi, hal ini biasa disebut dengan knowledge self-efficacy (Lee dkk., 2006; dalam Cheung dan Lee, 2012).

\section{Hipotesis}

Berdasarkan teori yang sudah diuraikan sebelumnya, penulis mengembangkan model pendahulu untuk tujuan melakukan e-WOM melalui media platform diskusi online salah satunya adalah Kaskus, pengembangan model ini didasari pada penelitian sebelumnya yang dilakukan oleh Cheung dan Lee (2012).

a. Egoism

Motif dianggap egoistik jika tujuan utamanya adalah untuk meningkatkan kesejahteraan aktor itu sendiri (Baston, 1994; dalam Cheung dan Lee, 2012). Orangorang berbagi dan menyumbangkan pengetahuan mereka karena mereka ingin mendapatkan pengakuan informal dan menetapkan dirinya sebagai ahli (Wasko dan Faraj. 2005; dalam Cheung dan Lee, 2012). Dengan demikian, penulis percaya bahwa jika seseoarang ingin mendapatkan reputasi dalam media sosial, maka dia memiliki kecendereungan yang lebih tinggi untuk melakukan e-WOM. Ini menggarah pada hipotes is:

H1. Persepsi mengenai peluang untuk meningkatkan reputasi seseorang berpengaruh positif terhadap niat konsumen melakukan e-WOM.

Motif lain dari tindakan egoistik adalah reciprocity (timbal balik), yang juga dipahami sebagai manfaat bagi individu untuk terlibat dalam hubungan sosial. Orang yang menawarkan bantuan kepada orang lain mengharapkan timbal balik dalam waktu yang lain (Lakhani; dalam Cheung dan Lee, 2012). Penelitian sebelumnya menemukan bahwa orang yang berbagi pengetahuan di komunitas online mengharapkan timbal balik (Wasko dan Faraj, 2005; dalam Cheung dan Lee, 2012). Dengan demikian, ini mengarah pada hipotesis:

H2. Persepsi mengenai peluang untuk mendapatkan timbal balik berpengaruh positif terhadap niat konsumen melakukan e-WOM.

b. Collectivism

Dalam hal melakukan sesuatu untuk publik, kolektivisme dapat dikaitkan dengan teori identitas sosial, dimana individu memperoleh identitas sosial dari kelompok yang mereka miliki (Tajfel dan Turner, 1986; dalam Cheung dan Lee, 2012). Setiap anggota dari suatu kelompok sosial memiliki perasaan bahwa kebutuhan orang lain akan terpenuhi melalui kontribusi mereka kepada kelompok (McMillan dan Chavis, 1986; dalam Cheung dan Lee, 2012).

Rasa memiliki (sense of belonging) mengacu pada rasa keterlibatan emosional dengan kelompok. Anggota jaringan elektronik yang berkomitmen mengambil bagian dalam berbagi pengetahuan karena mereka berpikir perilaku seperti itu yang terbaik bagi masyarakat. Oleh karena itu, orang-orang dengan 
motivasi intrinsik ini akan termotivasi untuk berpartisipasi dalam kegiatan berbagi dan membantu mitra kekerabatan mereka (Lakhani dan Hipper; dalam Cheung dan Lee, 2012). Dengan demikian, ini mengarah pada hipotesis:

H3. Persepsi mengenai rasa memiliki berpengaruh positif terhadap niat konsumen melakukan e-WOM.

c. Altruism

Individu yang bertindak atas tujuan altruistik bersedia menjadi sukarelawan untuk mengkontribusikan pengetahuan mereka secara online tanpa mengharapkan imbalan langsung sebagai imbalannya. Misalnya, konsumen dapat berbagi pengalaman pembelian hanya karena orang lain memiliki kebutuhan untuk itu (Kollock, 1999; dalam Cheung dan Lee, 2012). Kenikmatan membantu (enjoyment of helping) telah diakui oleh peneliti sebagai faktor altruistic menjelaskan keinginan individu untuk berbagi pengetahuan dalam jaringan elektronik atau ruang sosial online (Tong dkk, 2007; dalam Cheung dan Lee, 2012). Meskipun tidak ada kompensasi yang jelas, orang-orang dalam komunitas virtual masih mendapatkan kesenangan dan kepuasan intrinsik dengan membantu orang lain melalui berbagi pengetahuan mereka (Wasko dan Faraj, 2000; dalam Cheung dan Lee, 2012). Dengan demikian, ini mengarah pada hipotesis:

H4. Persepsi mengenai kenikmatan dalam membantu orang lain berpengaruh positif terhadap niat konsumen melakukan e-WOM.

d. Principlism

Aksi untuk melakukan sesuatu untuk publik dalam hal principlism dapat dijelaskan oleh komitmen normatif, di mana komitmen adalah rasa kewajiban kepada organisasi (Allen dkk, 1996; dalam Cheung dan Lee, 2012). Dengan rasa komitmen yang kuat terhadap komunitas, individu dalam komunitas online lebih mungkin merasa berkewajiban membantu orang lain dengan menyumbangkan pengetahuan (Dholakia, 2004; dalam Cheung dan Lee, 2012).

Kewajiban moral berasal dari principlism. Dalam konteks organisasi, orang melihat pengetahuan mereka sebagai barang publik dan mereka termotivasi unt uk memiliki pertukaran pengetahuan dengan orang lain karena kewajiban moral dan kepentingan masyarakat (Allen dkk, 1996; dalam Cheung dan Lee, 2012). Oleh karena itu, dapat dikatakan ketika seorang konsumen memiliki rasa tanggung jawab moral yang kuat, akan ada kesempatan yang lebih tinggi bagi mereka untuk melakukan e-WOM dalam platform opini konsumen online. Dengan demikian, ini mengarah pada hipotesis:

H5. Persepsi mengenai kewajiban moral berpengaruh positif terhadap niat konsumen melakukan e-WOM.

e. Knowledge Self-Efficacy

Dalam teori kognitif sosial, Self-Efficacy adalah penilaian pribadi atas keyakinan seseorang mengenai kemampuannya untuk mengatur dan melakukan serangkaian tindakan yang diperlukan untuk mencapai tipe-tipe kerja yang dimaksud (Bandura, 1986; dalam Cheung dan Lee, 2012). Knowledge Self-Efficacy dapat berfungsi sebagai motivator diri untuk kontribusi pengetahuan dalam platform online. Studi sebelumnya telah menggambarkan pentingnya Knowledge SelfEfficacy terhadap niat seseorang untuk berbagi pengetahuan (Kankanhalli dkk, 2005; 
dalam Cheung dan Lee, 2012). Cheung dan Lee (2012) mengatakan bahwa jika Knowledge Self-Efficacy mengenai pengalaman pembelian tinggi, maka kecenderungan untuk melakukan e-WOM juga tinggi. Dengan demikian, ini mengarah pada hipotesis:

H6. Persepsi mengenai knowledge Self-Efficacy berpengaruh positif terhadap niat konsumen melakukan e-WOM.

\section{METODE PENELITIAN}

\section{Tempat, Waktu dan Subjek Penelitian}

Penelitian ini dilakukan pada pengguna Kaskus di Indonesia, dengan jumlah sampel sebanyak 100 responden yang diharapkan mampu mewakili populasi yang ada. Detail demografi responden disajikan pada tabel 1. Waktu penelitian mulai dari September hingga Desember 2018.

\section{Teknik Analisis Data}

Teknik analisis yang digunakan dalam penelitian ini adalah analisis ekplanatori dan prediksi. Penelitian eksplanatori dilakukan untuk melihat besar hubungan antara the public good dengan knowledge self efficacy dengan niat konsumen melakukan electronic word of mouth (e-WOM) pada pengguna Kaskus di Indonesia. Sementara analisis partial least square (PLS), untuk tujuan prediksi, pendekatan PLS lebih cocok digunakan sebagai teknik analisis data dalam suatu penelitian. Dengan pendekatan PLS diasumsikan bahwa semua varians adalah varians yang berguna untuk dijelaskan (Ghozali, 2014:31). Pengujian outer model dilakukan untuk melakukan uji validitas dan uji reliabilitas, kemudian pengujian inner model dilakukan dengan model boostrapping untuk pengujian hipotesis.

Dalam penelitian pernyataan kuesioner mengenai the public good (reputasi, timbal balik, rasa memiliki, kenikmatan membantu orang lain, prinsip moral) dan knowledge self efficacy menggunakan 18 item pernyataan. Sementara untuk pernyataan niat konsumen melakukan electronic word of mouth (e-WOM) menggunakan 3 item pernyataan. Skala yang digunakan terdiri dari 5 skala likert. Untuk pernyataan the public good (reputasi, timbal balik, rasa memiliki, kenikmatan membantu orang lain, prinsip moral) dan knowledge self efficacy serta niat konsumen melakukan electronic word of mouth (e-WOM) skala tersebut terdiri dari sangat tidak setuju (1), tidak setuju (2), cukup setuju (3), setuju (4) dan sangat setuju (5). Dalam proses pengolahan data penulis menggunakan SmartPLS 3.

Tabel 1. Aspek Demografi

\begin{tabular}{|c|c|c|c|}
\hline $\begin{array}{c}\text { Faktor } \\
\text { Demografi }\end{array}$ & Klasifikasi & $\begin{array}{c}\text { Jumlah } \\
\text { Responden }\end{array}$ & $\%$ \\
\hline \multirow{4}{*}{ Usia } & $12-18$ Tahun & 12 & $12 \%$ \\
\cline { 2 - 4 } & $19-24$ Tahun & 72 & $72 \%$ \\
\cline { 2 - 4 } & $25-30$ Tahun & 6 & $6 \%$ \\
\cline { 2 - 4 } & $>30$ Tahun & 0 & $0 \%$ \\
\hline \multirow{2}{*}{ Jenis Kelamin } & Pria & 60 & $60 \%$ \\
\cline { 2 - 4 } & Wanita & 40 & $40 \%$ \\
\hline
\end{tabular}


Lanjutan Tabel 1. Aspek Demografi

\begin{tabular}{|c|c|c|c|}
\hline $\begin{array}{c}\text { Faktor } \\
\text { Demografi }\end{array}$ & Klasifikasi & $\begin{array}{c}\text { Jumlah } \\
\text { Responden }\end{array}$ & $\%$ \\
\hline \multirow{4}{*}{ Pendidikan } & SMK/SMA & 38 & $38 \%$ \\
\cline { 2 - 4 } & D3 & 11 & $11 \%$ \\
\cline { 2 - 4 } & S1 & 49 & $49 \%$ \\
\cline { 2 - 4 } & S2 & 2 & $2 \%$ \\
\hline \multirow{4}{*}{ Pekerjaan } & Pelajar/Mahasiswa & 68 & $68 \%$ \\
\cline { 2 - 4 } & Wiraswasta & 23 & $7 \%$ \\
\cline { 2 - 4 } & Pegawai Swasta & 7 & $2 \%$ \\
\cline { 2 - 4 } & $\begin{array}{c}\text { Pegawai Negeri } \\
\text { Sipil }\end{array}$ & 2 & $7 \%$ \\
\hline
\end{tabular}

Sumber: Hasil Penelitian, diolah (2018)

Berdasarkan hasil penelitian ini diketahui karakteristik responden berdasarkan jenis kelamin didominasi oleh pria sebesar $60 \%$ dan wanita $40 \%$. Kemudian untuk karaktetistik berdasarkan pendidikan didominasi dengan pendidikan S1 sebesar 49\%, dilanjutkan dengan SMK/SMA sebesar 38\%. Kemudian untuk karakteristik responden berdasarkan pekerjaan didominasi dengan pelajar/mahasiswa yaitu sebesar $68 \%$, hal ini sejalan dengan karakteristik responden berdasarkan pendidikan bahwa pendidikan S1 dengan pekerjaan pelajar/mahasiwa mendominasi.

\section{HASIL PENELITIAN DAN PEMBAHASAN Hasil Penelitian}

Dalam penelitian ini pengujian inner model dievaluasi dengan mengunakan Rsquare untuk konstruk dependen dan uji t serta signifikansi dari koefisien parameter jalur struktural (dengan melihat p-value < 0.05). Adapun hasil dari R-square dapat dilihat pada tabel 2 dan hasil Inner Weight dapat diliat pada tabel 3.

Tabel 2. Nilai R-square

\begin{tabular}{|c|c|}
\hline Variabel & R-square \\
\hline $\begin{array}{c}\text { Niat Konsumen } \\
\text { Melakukan e-WOM }\end{array}$ & 0.279 \\
\hline
\end{tabular}

Sumber: Hasil Penelitian, diolah (2018)

Tabel 2 menunjukkan nilai R-square sebesar 0.279 atau sebesar 27,9\%. Hasil ini menunjukkan bahwa $27.9 \%$ variabel niat konsumen melakukan e-WOM dapat dipengaruhi oleh variabel reputasi, rasa memiliki, dan kenikmatan membantu orang lain, sisanya sebesar $72.1 \%$ dipengaruhi oleh faktor lain diluar model dalam penelitian ini. Hasil R-square dalam penelitian ini sebesar 0.279 berarti dapat diindikasikan bahwa variabel niat konsumen melakukan e-WOM dapat dipengaruhi moderat cenderung lemah oleh variabel reputasi, rasa memiliki, dan kenikmatan membantu orang lain. 
Tabel 3. Result for Inner Weight

\begin{tabular}{|c|c|c|c|c|c|}
\hline & $\begin{array}{c}\text { Estimasi } \\
\text { Sampel } \\
\text { Asli (O) }\end{array}$ & $\begin{array}{c}\text { Rata-Rata } \\
\text { Sampel } \\
(\mathrm{M})\end{array}$ & $\begin{array}{c}\text { Standar } \\
\text { Deviasi } \\
\text { (STDEV) }\end{array}$ & $\begin{array}{c}\text { T Statistik } \\
(\mid \mathrm{O} / \text { STDEV })\end{array}$ & $\begin{array}{c}\text { P } \\
\text { Values }\end{array}$ \\
\hline $\begin{array}{c}\text { Reputasi -> Niat } \\
\text { Konsumen } \\
\text { Melakukan e- } \\
\text { WOM }\end{array}$ & 0.215 & 0.215 & 0.100 & 2.148 & 0.016 \\
\hline $\begin{array}{c}\text { Timbal Balik -> } \\
\text { Niat Konsumen } \\
\text { Melakukan e- } \\
\text { WOM }\end{array}$ & -0.105 & -0.072 & 0.100 & 1.040 & 0.149 \\
\hline $\begin{array}{c}\text { Rasa Memiliki -> } \\
\text { Niat Konsumen } \\
\text { Melakukan e- } \\
\text { WOM }\end{array}$ & 0.255 & 0.268 & 0.099 & 2.581 & 0.005 \\
\hline $\begin{array}{c}\text { Kenikmatan } \\
\text { Membantu -> } \\
\text { Niat Konsumen } \\
\text { Melakukan e- } \\
\text { WOM }\end{array}$ & 0.343 & 0.314 & 0.100 & 3.442 & 0.000 \\
\hline $\begin{array}{c}\text { Prinsip Moral-> } \\
\text { Niat Konsumen } \\
\text { Melakukan e- } \\
\text { WOM }\end{array}$ & -0.032 & -0.017 & 0.103 & 0.312 & 0.377 \\
\hline $\begin{array}{c}\text { Knowledge Self } \\
\text { Efficacy -> Niat } \\
\text { Konsumen } \\
\text { Melakukan e- } \\
\text { WOM }\end{array}$ & 0.070 & 0.064 & 0.114 & 0.615 & 0.269 \\
\hline
\end{tabular}

Sumber: Hasil Penelitian, diolah (2018)

Berdasarkan hasil pada tabel 3 dapat dilihat bahwa p-value sebesar 0.016, dengan arah hubungan positif yang dapat dilihat melalui nilai original sample estimate $(\mathrm{O})$, yaitu sebesar 0.215 . P-value tersebut $<0.05$, berarti dalam penelitian ini reputasi berpengaruh positif terhadap niat konsumen melakukan e-WOM, artinya sesuai dengan Hipotesis 1 (H1) dimana persepsi mengenai peluang untuk meningkatkan reputasi seseorang berpengaruh positif terhadap niat konsumen melakukan e-WOM. Hal ini berarti Hipotesis 1 (H1) diterima.

Berdasarkan hasil pada tabel 3 dapat dilihat bahwa p-value sebesar 0.149 dengan arah hubungan negatif yang dapat dilihat melalui nilai original sample estimate $(\mathrm{O})$, yaitu sebesar -0.105 . P-value tersebut $>0.05$, berarti dalam penelitian ini timbal balik tidak berpengaruh positif terhadap niat konsumen melakukan e-WOM, artinya tidak sesuai dengan $\mathrm{H} 2$, dimana persepsi mengenai peluang untuk mendapatkan timbal balik berpengaruh positif terhadap niat konsumen melakukan e-WOM. Hal ini berarti hipotesis $2(\mathrm{H} 2)$ ditolak. 
Berdasarkan hasil pada tabel 3 dapat dilihat bahwa p-value sebesar 0.005 dengan arah hubungan positif yang dapat dilihat dari nilai original sample estimate $(\mathrm{O})$, yaitu sebesar 0.255 . P-value tersebut $<0.05$, berarti dalam penelitian ini timbal balik berpengaruh positif terhadap niat konsumen melakukan e-WOM, artinya sesuai dengan $\mathrm{H} 3$, dimana persepsi mengenai rasa memiliki berpengaruh positif terhadap niat konsumen melakukan e-WOM. Hal ini berarti Hipotesis 3 (H3) diterima.

Berdasarkan hasil pada tabel 3 dapat dilihat bahwa p-value sebesar 0.000 dengan arah hubungan positif yang dapat dilihat dari nilai original sample estimate $(\mathrm{O})$, yaitu sebesar 0.343 . P-value tersebut $<0.05$, berarti dalam penelitian ini kenikmatan membantu orang lain berpengaruh positif terhadap niat konsumen melakukan e-WOM, artinya sesuai dengan $\mathrm{H} 4$, dimana persepsi mengenai kenikmatan membantu orang lain berpengaruh positif dengan niat konsumen melakukan e-WOM. Hal ini berarti Hipotesis $4(\mathrm{H} 4)$ diterima.

Berdasarkan hasil pada tabel 3 dapat dilihat bahwa p-value sebesar 0.377 dengan arah hubungan negatif yang dapat dilihat dari nilai original sample estimate (O) sebesar -0.032 . P-value tersebut $>0.05$, berarti dalam penelitian ini persepsi prinsip moral tidak berpengaruh positif terhadap niat konsumen melakukan e-WOM, artinya tidak sesuai dengan H5, dimana persepsi mengenai kewajiban moral berpengaruh positif terhadap niat konsumen melakukan e-WOM. Hal ini berarti hipotesis 5 (H5) ditolak.

Berdasarkan hasil pada tabel 3 dapat dilihat bahwa p-value sebesar 0.269 dengan nilai original sample estimate $(\mathrm{O})$ sebesar 0.070. P-value tersebut $>0.05$, berarti dalam penelitian ini persepsi knowledge self efficacy tidak berpengaruh positif terhadap niat konsumen melakukan e-WOM, artinya tidak sesuai dengan H6, dimana persepsi mengenai knowledge self-efficacy berpengaruh positif terhadap niat konsumen melakukan e-WOM. Hal ini berarti hipotesis 6 (H6) ditolak.

\section{Pembahasan}

Hasil penelitian ini menunjukkan bahwa niat konsumen melakukan electronic word of mouth (e-WOM) dipengaruhi oleh kenikmatan membantu orang lain, rasa memiliki, dan reputasi dengan varians sebesar 27.9\%. Sedangkan timbal balik, prinsip moral dan knowledge self efficacy tidak berhubungan dengan niat konsumen melakukan electronic word of mouth (e-WOM). Nilai sebesar $27.9 \%$ atau 0.279 dapat diindikasikan bahwa variabel niat konsumen melakukan e-WOM dapat dipengaruhi moderat cenderung lemah oleh variabel reputasi, timbal balik, rasa memiliki, kenikmatan membantu orang lain, prinsip moral, dan knowledge self-efficacy, hal ini berarti sebagian besar niat konsumen melakukan electronic word of mouth (e-WOM) berhubungan dengan faktor lain diluar penelitian ini.

Hal ini berarti pengguna/member Kaskus melakukan e-WOM di Kaskus karena mereka memiliki kenikmatan tersendiri ketika membantu pengguna/member Kaskus lain di Kaskus, memiliki rasa memiliki yang cukup tinggi dengan antar pengguna/member Kaskus, dan sebagian kecil karena mereka ingin meningkatkan atau bahkan merubah reputasi dan status sosial mereka.

Hasil penelitian ini mendukung penelitian sebelumnya yang dilakukan oleh Cheung dan Lee (2012) menjelaskan bahwa niat konsumen melakukan e-WOM 
berhubungan secara positif dengan kenikmatan membantu orang lain, rasa memiliki, dan reputasi.

\section{KESIMPULAN DAN SARAN \\ Kesimpulan}

Berdasarkan hasil penelitian yang didapatkan bahwa niat konsumen melakukan e-WOM berpengaruh positif dengan kenikmatan membantu, kenikmatan membantu orang lain, rasa memiliki, dan reputasi. Hasil penelitian ini mendukung hipotesis H1, $\mathrm{H} 3$, dan $\mathrm{H} 4$ yang telah ditentukan sebelumnya oleh peneliti yang menyatakan adanya pengaruh positif antara kenikmatan membantu orang lain, rasa memiliki, dan reputasi dengan niat konsumen melakukan e-WOM. Sedangkan hasil penelitian ini tidak mendukung hipotesis $\mathrm{H} 2, \mathrm{H} 5$, dan $\mathrm{H} 6$ yang telah ditentukan oleh sebelumnya oleh peneliti yang menyatakan adanya hubungan positif antara timbal balik, prinsip moral, dan knowledge self efficacy.

Pengguna/member Kaskus mempunyai niat untuk melakukan e-WOM karena beberapa faktor yaitu antara kenikmatan membantu orang lain, rasa memiliki, dan reputasi, artinya (1) pengguna/member Kaskus menyebarkan e-WOM kepada pengguna/member Kaskus lain hanya untuk mendapatkan kesenangan atau kepuasan intrinsik dengan membantu orang lain dalam membagikan pengalaman / pengetahuan / informasi, (2) pengguna/member Kaskus menyebarkan e-WOM karena mereka merasa mereka terikat dengan komunitas yang sudah mereka bentuk di Kaskus, mereka juga merasa bahwa seluruh pengguna/member Kaskus memiliki tujuan yang sama, salah satu tujuan tersebut adalah untuk bertukar pengalaman/pengetahuan/informasi, mereka merasa bahwa hubungan mereka dengan pengguna/member lain di Kaskus berarti bagi mereka dan mereka juga merasa bahwa mereka adalah bagian dari Kaskus, (3) pengguna/member Kaskus memiliki sifat egoism yang cukup tinggi, mereka yang menyebarkan e-WOM untuk pengguna/member lain sebenarnya karena mereka ingin menaikkan status sosial mereka, mereka senang jika dianggap sebagai ahli dari apa yang sebarkan, mereka akan merasa pengguna/member lain di Kaskus selalu membutuhkan mereka.

\section{Saran}

Kaskus diharapkan agar terus mampu menyesuaikan diri dengan situasi dunia digital masa kini yang dipadati oleh media sosial, Kaskus harus selalu mampu mengedepankan keunikan sebagai arena diskusi yang memang selama ini menjadi kekuatan utama Kaskus agar Kaskus menjadi pilihan utama ketika orang-rang ingin melakukan diskusi atau bahkan ingin membagikan pengalaman mereka tentang hal apapun.

1. Untuk menambahkan rasa kenikmatan membantu orang lain, Kaskus sebaiknya menyediakan mekanisme dimana pengguna/member Kaskus yang susah menyebarkan e-WOM/pengetahuan/informasi untuk pengguna/member Kaskus lain dapat mengetahui bahwa e-WOM/pengetahuan/informasi yang mereka sebarkan memang benar membantu pengguna/member Kaskus lain.

2. Untuk meningkatkan rasa memiliki antar pengguna/member Kaskus, Kaskus sebaiknya sudah mulai harus membuatnya agar seperti media sosial yang dapat 
mendesain bagian foto profil yang diperbesar agar sesama pengguna/member Kaskus dapat melihat dengan jelas dengan siapa ia berintraksi, dapat membuat grup di dalam forum, atau bahkan dapat menambahkan pengguna/member Kaskus lain sebagai teman/teman dekat.

3. Untuk meningkatkan reputasi seorang pengguna/member Kaskus, Kaskus dapat menyediakan mekanisme rating untuk pengguna/member Kaskus yang sudah menyebarkan e-WOM/pengetahuan/informasi.

4. Untuk seluruh pengguna/member Kaskus dan seluruh konsumen diluar Kaskus yang mempunyai niat melakukan e-WOM sebaiknya mengetahui apa yang menjadi faktor pendorong anda melakukan penyebaran e-WOM/pengetahuan/informasi tersebut, sehingga jelas juga tujuan anda melakukan hal tersebut.

\section{DAFTAR PUSTAKA}

Cheung, M.C.K dan M.K.O Lee. 2012. What Drives Customer to Spread Electronic Word of Mouth in Online Customer-Opinion Platforms. Decision Support Systems 53 218-225.

Ghozali, I. 2014. Structural Equation Modelling Metode Alternatif Dengan Partial Least Squares (PLS). Edisi empat. Semarang:Badan Penerbit Universitas Diponegoro.

Hasan, A. 2013. Marketing dan Kasus Kasus Pilihan. Yogyakarta:CAPS.

Humaira, A. dan Wibowo, L.A. 2016. Analisis Faktor Elektronik Word Of Mouth (EWOM) Dalam Mempengaruhi Keputusan Berkunjung Wisatawan. Tourism and Hospitality Essentials (THE) Journal, Vol. VI, No.2.

Jalilvand, M.R. dan Samiei, N. 2012. The Effect of Electronic Word of Mouth on Brand Image and Purchase Intention. Marketing Intelligence \& Planning, 30 (4).

Kotler, P. dan Keller, K.L. 2016a. A Framework For Marketing Management. $6^{\text {th }}$ Edition/Global Edition. England:Pearson Education Limited.

Kotler, P. dan Keller. K.L. 2016b. Marketing Management. $15^{\text {th }}$ Edition. New Jersey:Person Pretice Hall, Inc.

Prisgunanto, I. 2014. Komunikasi Pemasaran Era Digital. Jakarta:Prisani Cendekia.

Sunyoto, D. 2015. Strategi Pemasaran. Jakarta: CAPS.

Wijaya, T. dan Paramitha, E.L. 2014. Pengaruh Electronic Word Of Mouth Terhadap Keputusan Pembelian Kamera DSLR. Jurnal Pemasaran 2 (1). 